\title{
Urinary Tract Infection and Antibiotic Susceptibility at Nepalgunj Medical College and Teaching Hospital, Kohalpur
}

\author{
Mahaseth $\mathrm{BK}^{1}$, Srivastava $\mathrm{M}^{2}$, Das $C \mathrm{R}^{3}$, Rawat $\mathrm{D}^{4}$
}

\begin{abstract}
INTRODUCTION: In developing countries, urinary tract infections (UTIs) are one of the most commonly diagnosed diseases among the patient seeking medical service and are treated with empirical antibiotics which does not provides cure and causes resistance. Objective: To find out the incidence of urinary tract infections and antibiotics sensitivity pattern among bacterial pathogens isolated in patients attending Nepalgunj Medical College and Teaching Hospital, Kohalpur. Methodology: All patients (both male and female) were included in the study with the clinical suspicion of UTI. They had their urine culture done. Incidence of UTI and spectrum of pathogens with their sensitivity were recorded. Result: A total number of 1445 patients were clinically suspected for UT. they had their urine cultura and sensitivity done Total number of patients with culture positive was 391(27.05\%). The majority of isolates were from female patients comprising of 314(80.3\%) patients. The most common pathogenic microorganism isolated was E.coli (73.65\%). Second most common organism was Klebsiella (19.9\%), it was followed by Acinetobacter (3.5\%), Enterobacter (3.06\%),Pseudmonas and Proteus (0.76\%) each, Staphylococcus $(0.05 \%)$ salmonella $(0.02 \%)$. The isolated microorganisms showed maximum sensitivity to Nitrofurantin and Amikacin. The isolated microorganism demonstrated resistance to cefpodoxime and Cefotaxime. Conclusion: Urinary tract infections is a commonly encountered case in general practice Females are more commonly affected than men. The microbial profile and the antibiotic sensitivity pattern must be taken into account while planning for the management. Regular supervision of the sensitivity pattern of pathogenic microorganism is mandatory for effective treatment.
\end{abstract}

Key words: Susceptibility, urinary tract infection, uropathogens

\section{INTRODUCTION}

In developing countries urinary tract infections (UTIs) are one of the most commonly diagnosed diseases among the patient seeking medical service ( frequency 180 per10, 000) ( $^{1.2}$. Females are more commonly affected compared to males. UTIs can be categorized as acquired or nosocomial. E.coli is the most common organism responsible for UTI in both sexes. Klebsiella and Proteus are responsible pathogens in community acquired infection and in nosocomial group are Pseudomonas, Proteus, and Enterobacter ${ }^{3}$.

Increasing resistance to antibiotics and frequent change in the sensitivity pattern of the bacteria are great problems in UTI. General practitioner should take into account about the microbial profile and the antibiotics sensitivity pattern during the management ${ }^{4}$. So, it is necessary to look for the most sensitive antibiotics for proper treatment for the UTIs in general practice ${ }^{5}$. This study was carried out to find out the

\footnotetext{
1. Dr. Binod Mahaseth

2. Prof. Madhuri Srivastava

3. Prof. C. R. Das

5. Dr. Durga Rawat
}

Address for correspondence:

Dr. Binod Mahaseth

Department of Obst. \& Gynae.

Nepalgunj Medical College

Kohalpur, Banke, Nepal

Email: mahasethashabinod.js@gmail.com incidence of urinary tract infection and antibiotics susceptibility pattern among bacterial pathogens isolated in patients attending Nepalgunj Medical College Teaching Hospital, Kohalpur.

\section{MATERIAL AND METHODS}

This is a cross-sectional study carried out at Nepalgunj Medical College Teaching Hospital, Kohalpur. All patient seeking health services in different departments of Nepalgunj Medical College Teaching Hospital, Kohalpur. This study included male and female patients suspected clinically having UTI symptoms viz history of burning micturition, increased frequency, lower abdominal pain, and frequent fever. Their urine was collected and sent for culture and sensitivity and results were analysed. This study included 191708 both males and females attending NGMC from May 2015 to May 2016.

\section{RESULTS}

out of 191708 patients, clinically 1445 patients were suspected to have UTI. Out of 1445 patients the number of males were $266(18.04 \%)$ and the number of females was $1179(77.96 \%)$. Out of these 1445, 391 samples grew positive culture. the number of males was $77(19.69 \%)$ and number of females 314(80.31\%) (figure 1). 


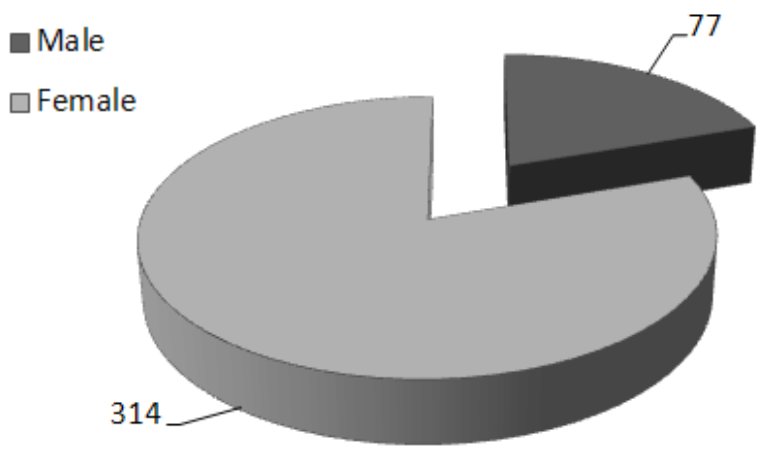

Figure 1: Gender distribution of positive urine culture isolated in Male77, 19.6\% and in Female 314, 80.3\%

\begin{tabular}{|l|c|c|}
\hline Microorganism & Number & $\%$ \\
\hline E .coli & 276 & 70.58 \\
\hline Klebsiella & 80 & 20.97 \\
\hline Acinetobacter & 13 & 3.32 \\
\hline Enterobacter & 11 & 2.81 \\
\hline Pseudomonas & 3 & 0.76 \\
\hline Proteus & 3 & 0.76 \\
\hline Staphylococcus & 2 & 0.05 \\
\hline Salmonella & 1 & 0.02 \\
\hline
\end{tabular}

Table I: Spectrum of microorganism in urine culture $(n=391)$

The culture report showed that E Coli is the commonest offender 276(70.58\%). Second most common organism was Klebsiella $82(20.97 \%)$ cases. It was followed by Acinetobacter $13(3.32 \%)$, Enterobacter 11 (2.8\%), Pseudomonas and Proteus $3(0.76 \%)$ each, Staphylococcus $2(0.05 \%)$ salmonella $1(0.02 \%)$.

Table II shows that the maximum sensitivity is with microorganism Nitrofurantin $(175,49.1 \%)$ followed by Amikacin $(157,40.1 \%)$. The most common pathogenic microorganism E Coli isolated in our study demonstrated resistance with Cefpodoxime $(90,23.01 \%$ and Cefotaxime (89, 22.76\%) (Table II).

Isolated microorganism showed maximum number of sensitivity with the antibiotics Nitrofurantin and Amikacin. The most common pathogenic microorganism isolated in our study demonstrated resistance with Cefpodoxime and Cefotaxime.

\section{DISCUSSION}

In the present study of 1445 clinically suspected UTI cases uropathogens were isolated in 391 (27.05\%) cases. Female patients comprised of $80.3 \%$ positive culture, and in males 77 $19.7 \%$.

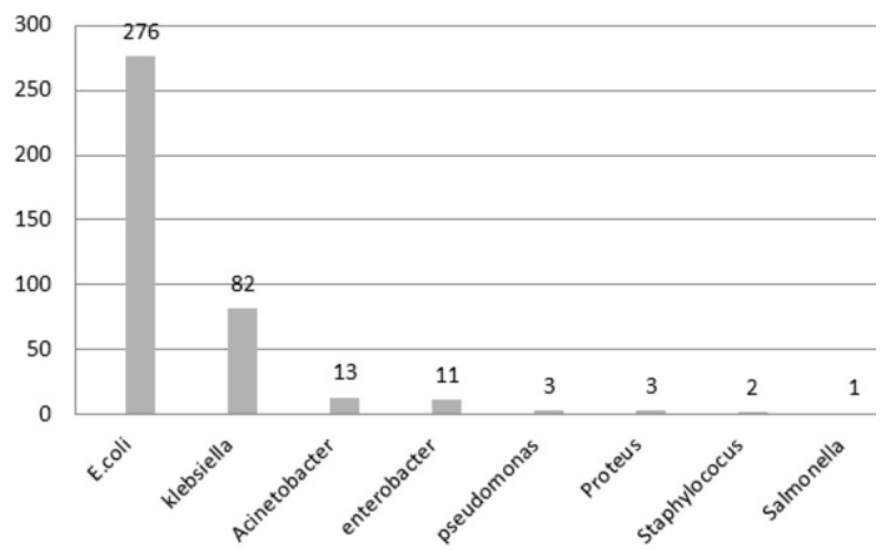

Figure 2: Microorganism growth in urine culture

Subedi $\mathrm{N}$ et al and Raza $\mathrm{S}$ et $\mathrm{al}^{5,6}$ have reported culture positive in $17.4 \%$ cases and $19.7 \%$ cases respectively. In our study the culture was found to be positive in $27.05 \%$. the rate is considerably higher in this part of Nepal showing that UTI is commoner. In the present study the rate of UTI in males was $19.7 \%$ and in females $80.31 \%$.

Khan G et al ${ }^{7}$ showed the infection rate in females to the tune of $77 \%$ and in males $22.8 \%$. In the present study E Coli was the commonest bacteria grown in culture $(n=276,70.5 \%)$.

Other workers have also reported that E Coli was the most frequently isolated ${ }^{3,7,10,11,12}$.

The antibiotic suscepbility in our study showed that the highest percentage of sensitivity was with Nitrofurantin (93.65\%), and with Amikacin (88.6\%). Raza $S$ et al ${ }^{5}$ showed that Amikacin is the most sensitive antibiotic. Subedi $\mathrm{N}$ et al ${ }^{6}$ in a study showed highest number of susceptibility with Piperacillin-Tazobactum and Ceftriaxone. In our studt Cefpodoxime and Cefotaxime showed a poor effectiveness.

Shaifali et al $\left.\right|^{3}$ in a study showed that highest susceptibility with Nitrofurantoin $86.9 \%$.

\section{CONCLUSION}

Urinary tract infection is a commonly encountered problem in the hospital patients. Females are more commonly affected than males. E. coli is the commonest uropathogen and Klebsiella is the next. Nitrofurantin and Amikacin were the most effective drug in our study for UTI. The physicians treating such cases in this area should bear this fact in mind. Regular sensitivity patterns are needed as the sensitivity of the bacteria keeps on changing.

\section{REFERENCES}

1. Bader MS, Hawboldt J, Brooks A. Management of complicated urinary tract infections in the era of antimicrobial resistance. Postgrad Med. 2010;122(6):7-15. 
Mahaseth et al.: Urinary Tract Infection and Antibiotic Susceptibility in Nepalgunj Medical College and Teaching Hospital, Kohalpur

\begin{tabular}{|c|c|c|c|}
\hline Antibiotic & Intermediate & Resistant & Sensitive \\
\hline NIT & 30 & 13 & 162 \\
\hline PB & 39 & 43 & 15 \\
\hline GEN & 7 & 22 & 24 \\
\hline CXM & 29 & 89 & 12 \\
\hline CAZ & 2 & 35 & \\
\hline CTR & 4 & 79 & 65 \\
\hline $\mathrm{CPD}$ & 11 & 90 & 8 \\
\hline MRP & 5 & 32 & 30 \\
\hline LE & 22 & 55 & 70 \\
\hline $\mathrm{NX}$ & 20 & 39 & 46 \\
\hline GAT & 4 & 3 & 6 \\
\hline CLR & 13 & 77 & 13 \\
\hline $\mathrm{CIP}$ & 9 & 64 & 75 \\
\hline $\mathrm{C}$ & 1 & 29 & 37 \\
\hline OF & 5 & 10 & 6 \\
\hline CTX & 3 & 75 & 40 \\
\hline $\mathrm{AK}$ & 23 & 20 & 134 \\
\hline TOB & 41 & 13 & 49 \\
\hline AZM & & 3 & 1 \\
\hline VA & 2 & 17 & \\
\hline AMX & 1 & 19 & \\
\hline CFM & 9 & 59 & 33 \\
\hline AMC & 1 & 19 & \\
\hline PIT & 28 & 33 & 34 \\
\hline $\operatorname{cox}$ & & 14 & \\
\hline COT & 1 & 20 & 10 \\
\hline DO & 35 & 35 & 43 \\
\hline $\mathrm{CZ}$ & 1 & 2 & 2 \\
\hline CPM & 3 & 21 & 7 \\
\hline NA & 3 & 40 & 11 \\
\hline
\end{tabular}

Table II: Antibiotic sensitivity pattern of isolated pathogenic microorganism

Abbreviaons: $A K=A m i k a c i n ; A M C=A m o x y c l a v ; A M P=A m p i c i l l i n ; A Z M=A z i t h r o m y c i n, C B=C a r b e n i c i l l i n ; C F M=C$ efixime; CTX=Cephotaxime; $C X=$ Cephoxitine; $C A Z=C$ eftazidime; CTR=Ceftriaxone; CIP=Ciprofloxacin; COT=Co-Trimoxazole; GEN=Gentamycin; NA=Nalidixic Acid; OF=Ofloxacin; NX=Norfloxacin; PI=Piperacillin; TOB=Tobramycin,Nit-nitrofurantin, $\mathrm{PB}=$ Polymyxin $\mathrm{B}, \mathrm{CXM}=$ Cefotaxime, $\mathrm{CPD}=$ Cefpodoxime, MRP= Meropenam, LEV= Levofloxacin, GAT= Gatifloxacin, CLR= Clarithromycin, $\mathrm{C}=$ Chloramphenicol, $\mathrm{DO}=$ doxycycline, $\mathrm{VA}=$ vancomycin

2. Bent $S$ et al. Urinary Tract Infections, Pyelonephritis, and Prostatis. In: Longo DL, Kasper DL, Jameson JL, Fauci AS, Hauser SL, Loscalzo J, editors. Harrison's Principle's of Internal Medicine. 18th ed. McGraw Hill: USA; 2012. p 4773-82. 3. Shaifali I, Gupta $\mathrm{U}$, Mahmood SE, Ahmed J. Anbioc susceptibility patterns of urinary pathogens in female outpatients. N Am J Med Sci. 2012 Apr; 4(4): 163-169.

4. Hummers-Pradier E, Kochen MM. Urinary tract infections in adult general practice patients. Br J Gen Pract. 2002 Sep; 52(482):75261.

5. Raza S, Pandey S, Bha CP. Microbiological analysis microbiological analysis of isolates in Kathmandu Medical College teaching hospital, Kathmandu, Nepal. Kathmandu University Med J (KUMJ). 2011 Oct-Dec; 9(36):295-7.

6. Subedi N, Pudasaini S. Bacteriological profile and antibiotic sensitivity pattern in patients with urinary tract infection. Journal of Pathology of Nepal (JPN). 2017 March; Vol. 7 (13); 10661069.

7. Khan G, Ahmad S, Anwar S. Frequency of uropathogens in different gender and age groups. Gomal J Med Sci. 2013 June; 11: 20-3.

8. Shah LJ, Vaghela GM, Mahida H. Urinary tract infecon: 
Bacteriological profile and its antibiotic susceptibility in Western India. National Journal of Medical Research (NJMR). Jan - March 2015; Volume 5(1): 71-4

9. Vasudevan R. Urinary Tract Infection: An Overview of the Infection and the Associated Risk Factors. J Microbiol Exp 1(2). 2014 May; 00008. DOI: 10.15406/jmen.2014.01.00008

10. Sabir S, Anjum AA, ljaz T, Ali MA, Khan MR, Nawaz M. Isolation and antibiotic susceptibility of $\mathrm{E}$. coli from urinary tract infections in a tertiary care hospital. Pak J Med Sci (pjms). 2014; 30(2): 389392.

11. Tada GD, Gandhi JP, Patel NK. A study on antibiotic related resistance in UTI paents: a comparison between community acquired and hospital acquired E coli. Nat J Com Med. 2012 AprilJune;3(2):255-8.

12. Behera PK, Panigrahi R, Mishra SN, Tripathy KP. ClinicoMicrobiological Profile of Community Acquired Urinary Tract Infection in The Elderly: A Hospital Based Study Journal of Dental and Medical Sciences. 2016 November; 15(11): 2934.DOI: 10.9790/0853-1511082934.

13. Divyashanthi CM, Adithiyakumar S, Bharathi N. Study of prevalence and antimicrobial suscepbility pattern of bacterial isolates in a terary care hospital. International journal of pharmacy and pharmaceutical sciences. 2015; 7(1): 185-90.

14. Somashekara SC, Deepalaxmi S, Jagannath N, Ramesh B, Laveesh MR, Govindadas D. Retrospecve analysis of antibioc resistance pattern to urinary pathogens in a Tertiary Care Hospital in South India. J Basic Clin Pharma. 2014 September- November; 5 (4):105-8.

15. Haque R, Akter ML, Salam MA. Prevalence and susceptibility of uropathogens: a recent report from a Teaching hospital in Bangladesh. BMC Res Notes. 2015; 8:416.DOI 10.1186/s13104015- 1408

16. Humayun $T$, Iqbal $A$. The culture and sensitivity pattern of urinary tract infections in females of reproducve age group. Ann Pak Inst Med Sci. 2012; 8(1): 19-22. 